\title{
Prevalence of Potential Drug-Drug Interactions in the Intensive Care Unit of a Tertiary Care Hospital: A Cross-Sectional Study
}

\author{
Swathi Acharya 1", Akshitha Sai Ragam', Rajendra Holla', Anith Raj Anantharam Bhat Yennagudda ${ }^{2}$ \\ 'Department of Pharmacology, K.S. Hegde Medical Academy, NITTE (Deemed to be University), Deralakatte, Mangalore, Karnataka, INDIA. \\ ${ }^{2}$ Consultant Radiologist, Taluk Hospital, Kundapura, Karnataka, INDIA.
}

\begin{abstract}
Objective: To analyze the various Potential Drug-Drug Interactions in ICU patients with the ultimate goal of raising awareness among clinicians on safe medication usage. Materials and Methods: This was a Cross-sectional study conducted at a tertiary care hospital. The medical records of the patients admitted to the ICU of the hospital from January 2017 to June 2017 formed material for the study, were analyzed using the database from Lexicomp $₫$ Solutions android mobile application for Potential Drug-Drug Interactions. Results: Among the 176 patients, $81.39 \%$ had Potential Drug-Drug Interactions, with cardiovascular drugs (22.6\%) being the majority group followed by respiratory drugs (17. $97 \%$ ). Among these $73.2 \%$ of the interactions were clinically relevant with the majority being moderate $(72.26 \%)$ in severity with fair $(72.6 \%)$ documentation and belonging to Category $\mathrm{C}$ $(61.080 \%)$ in risk rating. The pharmacodynamics type of interactions was more $(59.31 \%)$ than pharmacokinetic type (36.13\%). Conclusion: The high
\end{abstract}

prevalence of Potential Drug-Drug in the ICU setting emphasizes the need for effective medication management and pharmacological consultation to reduce the adverse effect and improve the therapeutic outcome in these patients.

Key words: Potential Drug-Drug Interaction, Severity,Documentation, Risk rating,Mechanism

Correspondence

Dr. Swathi Acharya, Assistant Professor, Department of Pharmacology, K.S Hegde Medical Academy, NITTE (Deemed to be university), Deralakatte, Mangalore, Karnataka, INDIA.

Phone: +91-9964498738

Email: acharyaswathi4@gmail.com

DOI: 10.5530/jyp.2019.11.41

\section{INTRODUCTION}

Drug-Drug Interaction (DDI) is an event in which effect of one drug is modified due to the concomitant administration of another drug. These interactions can lead to reduced, null, increased drug effect or adverse effects. ${ }^{1}$ DDIs influences the therapeutic efficacy of drugs that may lead to life-threatening adverse reactions or therapeutic failure. Many factors are responsible for Potential Drug-Drug Interactions (pDDI) like the number of drugs prescribed, age and comorbid disorders. Other determinant factors include the pharmacokinetic profile and the pharmacological characteristics of the medications. ${ }^{2}$ According to studies the prevalence of potential drugs interaction is 3-5\% in patients receiving 3-10 drugs. ${ }^{3}$ Lima et al. showed that the incidence of DDIs increases by $10 \%-20 \%$ in patients using 10-20 drugs. ${ }^{4}$

DDIs are common causes of adverse drug effects that may affect patient health; A study showed that $23 \%$ of clinically significant adverse events in ICU were related to drug interactions. ${ }^{5}$ Adverse drug reactions significantly prolong the length of hospital stay and cost of treatment and elevate the risk of death. In a study, 5-20\% of serious adverse drug reactions due to DDIs resulted in hospitalization or death. ${ }^{6}$ Hence, it is important to identify and prevent the of Potential Drug-Drug Interactions (pDDIs) which can improve patient safety. ${ }^{7}$

The ICU patients are particularly susceptible to the development of drug interactions, due to the severity of disease, polypharmacy, co-morbid conditions, chronic diseases, complex therapeutic regime and frequent modification in therapy. ${ }^{8}$

Prevalence of pDDI is varying in different parts of the world, $46.3 \%$ of ICU prescriptions included pDDIs in a study conducted in the USA. ${ }^{9}$ The prevalence of pDDI in Brazilian studies were around $67 \%$ or $70 \% .{ }^{10}$ Indian studies it is ranging between $70.06 \%$ to $90.02 \% .{ }^{11}$ It is difficult to recognize the symptoms of DDI in these patients as the symptoms get masked by their disease symptoms due to which pDDI go unnoticed; hence DDI poses a significant challenge to health care providers and may affect morbidity, mortality and patient's quality of life. ${ }^{12}$ Therefore, Consideration of DDIs for patients in the ICU is critical for their treatment. There is a need for the continuous assessment of pDDI in intensive care unit which helps in the early detection and reduction in the prescription of drugs with potential interactions. ${ }^{13}$ To conduct education actions linked to the awareness on the use of computerized systems to detect the presence of drug interactions and their implication in treatment. However, studies from the southern part of India are scarce and limited which necessities the need for critical evaluation of the prevalence of pDDIs in ICU. Hence the study was planned with the objective to assess the frequency of potential drug-drug interaction (pDDIs). To evaluate the clinically relevant pDDIs, document the frequently interacted drug combinations, categorize them according to onset, severity, documentation and based on the mechanism of interaction with the intention of helping to better the knowledge and awareness of intensivists in this area and minimize the adverse effects due to pDDIs.

\section{MATERIALS AND METHODS}

\section{Methods}

The present study was a Cross-sectional, observational study conducted at a tertiary care hospital. After obtaining the approval of the Institutional Ethics Committee, the data from the medical records of the patients admitted into the Intensive Care Unit (ICU) of the hospital from January 2017 to June 2017 were reviewed and one prescription per patient (As a convenient sampling process) was collected retrospectively and assessed 
as part of the study. The Prescription within $48 \mathrm{hrs}$ of admission to ICU was selected in all cases.

The data was entered into a performa designed for the study. Section 1 included the demographic and patient identification information such as Ip.no, age, gender and information about ICU admissions such as medical diagnosis, date of admission and no of days of hospital stay. Section 2 included the information of the drugs prescribed such as their name, dosage and frequency of administration. The Quantification and classification of the pDDIs were done using the database from Lexicomp Solution android mobile application version 4.1.2.

The data collected from patients' records were evaluated for:

a. The frequency of total pDDIs and clinically relevant pDDIs are classified according to ATC class, b. pDDIs were categorized into different levels as follows: Onset: Rapid/Delayed, Severity: Contradicted/ Major /Moderate/ Minor, Scientific evidence (Documentation): Excellent/ Good/Fair/Unlikely, Risk rating as X: Avoid combination, D: Therapy modification, C: Monitor therapy, B: No action needed, A: No known interaction. c. The frequently interacted drug-combinations, d. Based on the mechanism into pharmacokinetic, pharmacodynamics and not established/unclear. These data were transferred to the master chart and later subjected to analysis.

Drugs such as nutritional supplements, hydro-electrolytic components and vitamins were excluded from the analysis.

The descriptive statistical analysis was done using SPSS 21.0 for Windows. ' $p$ ' value $<0.05$ was considered statistically significant. The correlation between the incidence of drug-drug interactions with age, number of days of hospital stay, number of diagnoses and the number of drugs prescribed was analyzed using the Spearman correlation coefficient.

\section{RESULTS}

Total of 176 patients was included for the study admitted during the study period, 104 were males (59.1\%) and 72 were females (40.9\%) with age ranging from 19 years to 90 years with mean age of $56.09 \pm 15.39$ years. Majority of the patients were diagnosed with respiratory disorder (17.11\%) with most of them presenting with COPD with LRTI with/ without respiratory failure. Cardiovascular disorder (9.31\%) being the second most common presentation with an associated disorder like HTN (9.3\%) and Diabetes Mellitus (7.98\%).

The total number of the drugs prescribed were 1399 with the average number of drugs prescribed being 7.95 \pm 3.07 and the number of pDDI was 907 , among this $712(78.505 \%)$ were clinically relevant interactions. Around $81.2 \%$ of the patients had at least one pDDI interaction with the majority of the patients having drug interaction in the range of 1-5 (58.33\%). (Table 1, Figure 1).

The correlation between incidence of drug-drug interactions with age, number of drugs, number of diagnosis were $+0.378(p=0.0001),+0.813$ $(p=0.0001)$ and $+0.329(p=0.0001)$ indicating the positive relationship between the variables. Whereas, the Spearman correlation between Drug interaction and Numbers of days in ICU is -0.188 ( $p=0.013)$, which indicates that there is a negative relationship between the variables (Figure 2).

Out of 907 pDDI, 1.8\% of the interactions had rapid development and $0.88 \%$ had delayed development. In the Severity scale, the majority of interactions were of Moderate severity (72.26\%) followed by Major (17.42\%), Minor (9.15\%) and NA (1.32\%). Concerning the documentation of pDDI $72.26 \%$ had Fair documentation in literature followed by $21.27 \%$ good documentation and $4.41 \%$ excellent documentation. In risk rating majority were belonging to " $\mathrm{C}$ " Category $(61.08 \%)$ followed by " $\mathrm{B}$ " (19.95\%), "D" (16.64\%), "A" (1.54\%) and "X" (0.66\%). About $60.41 \%$ of the interactions were of pharmacodynamics mechanism and $36.16 \%$ of pharmacokinetics mechanism with a statistically significant difference among them. (Table 2)

The frequency of the drug interactions was more with the drugs belonging to cardiovascular drugs $(22.6 \%)$ followed by respiratory drugs (17.97\%). (Figure 3) But in the clinically relevant drug interaction majority were belonging to Cardiovascular drugs (25.9\%) followed by drugs affecting Hormonal system (13.32\%).

Among the 907 drug interactions, more frequently interacted drug combinations were Salbutamol + Budesonide (6.64\%) followed by Aspirin+ Clopidogrel (3.79\%) shown in Table 3. The clinically relevant pDDI seen more frequently with Aspirin + Clopidogrel followed by Azithromycin + Salbutamol and Clopidogrel +Pantoprazole.

\section{DISCUSSION}

Our study showed a high prevalence of pDDI (81.2\%) along with the presence of polypharmacy and the majority of pDDI were clinically relevant $(75.08 \%)$ which was almost similar to the studies done by Hamidy et al. ${ }^{14}$ Valizade et al. ${ }^{15}$ Gupta et al. ${ }^{16}$ in critically ill patients stressing to the need for increased awareness about the pDDI in health care providers. The reason may be due to the increased number of drugs prescribed per patients with the average number being $7.95 \pm 3.07$. Male patients had experienced more pDDI compared to female patients which were similar to the findings in Gupta $\mathrm{M}$ et al. ${ }^{16}$ but were contrast to the results of Bleich et al. ${ }^{17}$ This difference may be due to the increased number of male patients enrolled in our the study. In our study a positive correlation was seen between age and the incidence of pDDI which was similar to other study findings ${ }^{12,16}$ this may be due to alteration in the physiological state, associated comorbid disorders in elderly leading to the variation in pharmacodynamics and pharmacokinetic responses. A positive correlation was also present between the number of drugs and the number of diagnosis with the number of pDDI in our study which was similar to the findings in other studies. ${ }^{16,18,19}$ Increase in the number of diagnosis increases the number of prescribed drugs leading to increased chances of drug interactions and alteration in therapeutic response.

Table 1: Patient Characteristics Like Age, Number of Days in Hospital and Number of Drugs Involved in Interactions.

\begin{tabular}{cc}
\hline Mean average age & $55.88 \pm 15.33$ \\
Mean number of days in the hospital & $12.215 \pm \_9.67$ \\
Average number of diagnosis & 2.98 \\
$\begin{array}{c}\text { Mean number of drugs prescribed per } \\
\text { patient }\end{array}$ & $7.95 \pm 3.07$ \\
$\begin{array}{c}\text { Mean number of drug interaction per } \\
\text { patient }\end{array}$ & $5.19 \pm \_6.16$ \\
Mean number of clinically relevant pDDI & $4.085 \pm 5.13$ \\
\hline
\end{tabular}

Table 2: Different Mechanism of Drug Interaction.

\begin{tabular}{cccc}
\hline & Mean \pm SD & $\begin{array}{c}\text { Pearson Chi-square } \\
\text { value }\end{array}$ & $P$ Value \\
PK & $2.25 \pm 2.41$ & 770.50 & 0.0001 \\
PD & $2.87 \pm 4.51$ & & \\
\hline
\end{tabular}


Table 3: Few Important Drug Combinations Responsible for More Frequently Occurred Drug Interactions.

\begin{tabular}{|c|c|c|c|c|c|c|c|}
\hline SI.no & First drug & Second drug & $\begin{array}{c}\text { Number } \\
\text { (percentage) }\end{array}$ & $\begin{array}{l}\text { Risk } \\
\text { rating }\end{array}$ & Severity & Documentation & Mechanism \\
\hline 1 & Salbutamol & Budesonide & $46(6.46 \%)$ & B & Moderate & Fair & $\begin{array}{c}\text { Steroid increases the } \\
\text { hypokalaemia effect of } ß 2 \\
\text { agonists }\end{array}$ \\
\hline 2 & Aspirin & Clopidogrel & $27(3.79 \%)$ & $\mathrm{C}$ & Moderate & Fair & $\begin{array}{l}\text { The increasing Antiplatelet effect } \\
\text { increases the risk of bleeding }\end{array}$ \\
\hline 3 & Clopidogrel & Atorvastatin & $20(2.8 \%)$ & B & Moderate & Fair & $\begin{array}{l}\text { Atorvastatin reduces the } \\
\text { antiplatelet effect of Clopidogrel }\end{array}$ \\
\hline 4 & Salbutamol & Hydrocortisone & $20(2.8 \%)$ & B & Moderate & Fair & $\begin{array}{l}\text { Steroid increases the } \\
\text { hypokalemic effect of } ß 2 \text { agonists }\end{array}$ \\
\hline 5 & Azithromycin & Salbutamol & $20(2.8 \%)$ & $\mathrm{C}$ & Moderate & Fair & Qtc Prolongation \\
\hline 6 & Clopidogrel & Pantoprazole & $17(2.3 \%)$ & D & Major & Fair & $\begin{array}{l}\text { Pantoprazole inhibits the } \\
\text { metabolic activation of } \\
\text { Clopidogrel }\end{array}$ \\
\hline 7 & Ondansetron & Metronidazole & $16(2.2 \%)$ & $\mathrm{C}$ & Moderate & Fair & Qtc Prolongation \\
\hline 8 & Furosemide & Aspirin & $11(1.5 \%)$ & $\mathrm{C}$ & Moderate & Fair & $\begin{array}{c}\text { Salicylates reduces the diuretic } \\
\text { effect }\end{array}$ \\
\hline 9 & Tramadol & Ondansetron & $10(1.4 \%)$ & $\mathrm{C}$ & Moderate & Good & $\begin{array}{c}\text { Antiemetic reduces the analgesic } \\
\text { effect }\end{array}$ \\
\hline 10 & Hydrocortisone & Azithromycin & $10(1.4 \%)$ & $\mathrm{C}$ & Moderate & Fair & $\begin{array}{l}\text { Azithromycin inhibits the efflux } \\
\text { of hydrocortisone and increases } \\
\text { the concentration }\end{array}$ \\
\hline
\end{tabular}

According to the severity scale, around $72 \%$ of the drug interactions in our study were of moderate severity similar to other studies. ${ }^{16-18}$ Where the medical intervention will be needed to treat the effects hence treating physician should be able to differentiate the drug interaction from the new onset of disease for the proper management in these patients. Followed by $17.42 \%$ of the major severity where effects may result in death, hospitalization, therapeutic failure or permanent injury hence strict vigilance is required while administering the drugs causing this kind of interactions. Knowledge of Risk rating is important to minimize or prevent interactions, in our study around $61.08 \%$ interactions were under "C" category indicating the need of monitoring therapy which was similar to findings by Gupta et al. ${ }^{14}$ Haji Aghajani et al. ${ }^{20}$ and around $16.64 \%$ were under " $D$ " category which requires the modification in the treatment.

Discussing on the reliability of these interactions majority of the interactions $(72.26 \%)$ had fair documentation in the literature followed by good documentation (21.27\%) like other studies. ${ }^{16,20,21}$ Indicating good knowledge and a sophisticated computer-based drug interaction check software in the emergency settings with the good training to the health care providers can help in avoiding the drug interactions which are harmful a to these patients and also helps in optimizing treatment to them.

The majority of interactions were due to pharmacodynamics mechanisms similar to studies by Gupta et al. Bista et al. and Kothari et al. . $^{1622,23}$ indicating the need of the proper knowledge of the drugs while administering in critical settings which can prevent the many of the interactions and reduce the adverse consequences.

The majority of patients presented with the diagnosis of respiratory disorders $(17.11 \%)$ followed by cardiovascular diseases $(9.31 \%)$, but the most common group of drugs involved in interactions were cardiovascular drugs (22.6\%) followed by respiratory drugs (17.97\%) this may be due to the increased drug prescription for comorbid disorders like

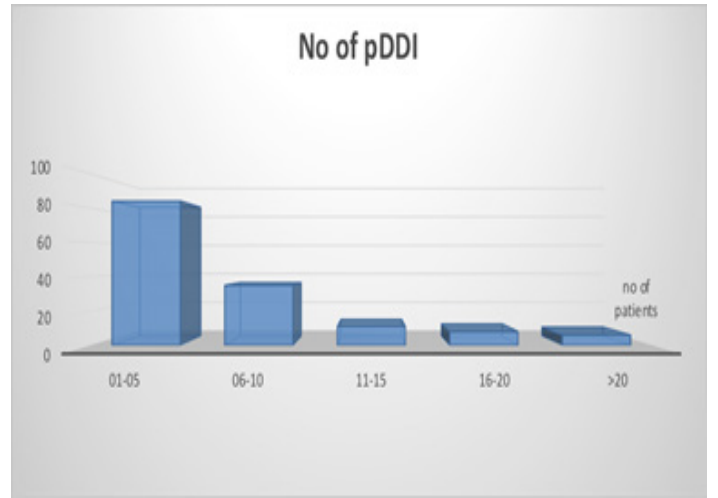

Figure 1: Categorization of Patients Depending on the Number of Drug Interactions Occured.

hypertension and diabetes in patients suffering from cardiovascular disorders. This finding was similar to the other studies by Gupta et al. Bista et al. Bleich et al. ${ }^{16-18}$

Cardiovascular drugs were mainly responsible for clinically relevant drug interaction. Antiplatelet drugs were most commonly involved drugs, mainly Clopidogrel with Aspirin and Clopidogrel with Pantoprazole followed by anti-infective drug Azithromycin with Salbutamol this was in similar to the findings of Baniasadi et al. ${ }^{24}$ but this was in contrast to the Valizade et al. ${ }^{14}$ were most commonly involved drugs were Ranitidine followed by Cephalosporin. Variations in patient's presentation, diagnosis, practices and use of medications between ICU settings may lead to different pDDIs patterns. ${ }^{9}$ Proton pump inhibitors are routinely used for critically ill patients to prevent stress-related mucosal damage. 


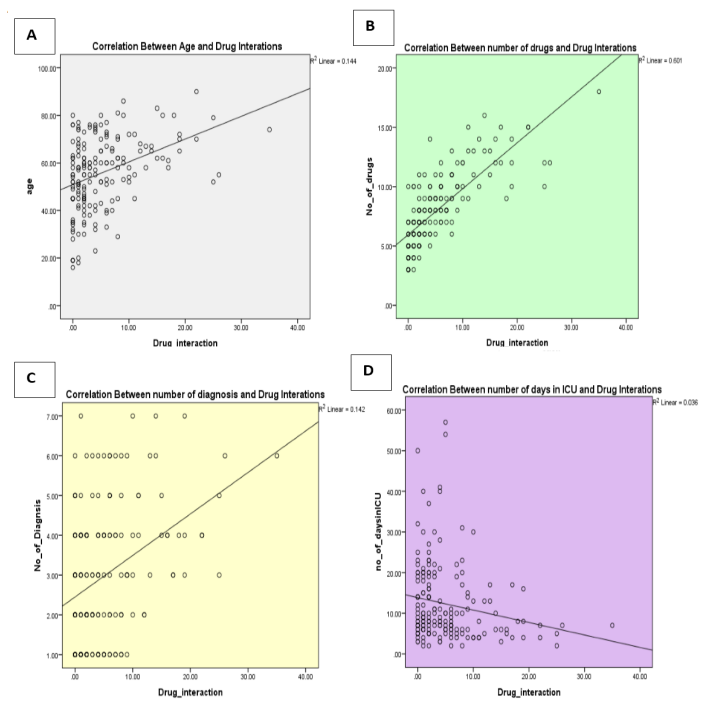

Figure 2: Association between Drug Interaction with Different Parameters like Age (A), Number of Drugs Prescribed (B), Number of Diagnosis (C) and Number of Days in ICU (D).

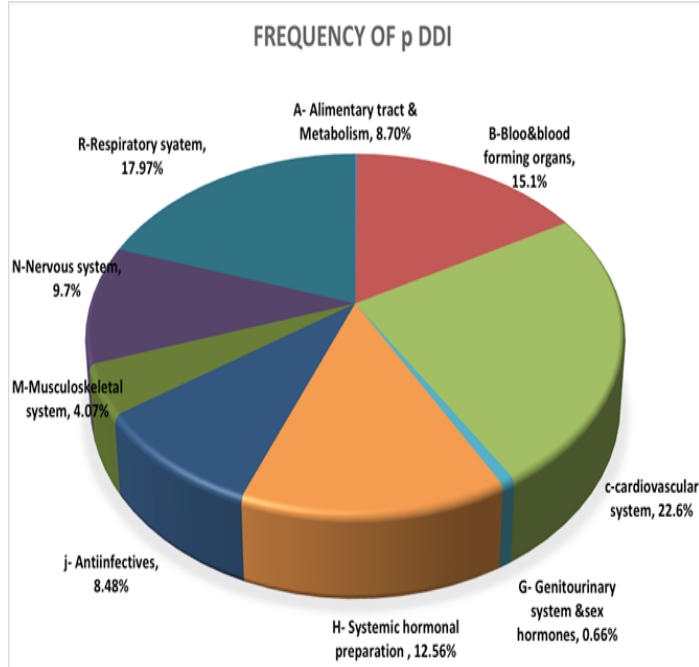

Figure 3: The Percentage of Drug Interactions Caused by Different Groups of the Drugs.

But these might cause potential drug interaction either by neutralizing $\mathrm{pH}$ of the stomach which alters the absorption of drugs or by inter fering with activation of the concurrently administered drug. Azithromycin + Salbutamol mainly a pharmacokinetic interaction leading to Qtc prolongation. Qtc prolongation is one of the important interactions to be dealt with as many other drugs are responsible for these adverse effects like Ondansetron and Metronidazole etc.

Hence our study necessitates the importance of knowledge on important drug interactions in the critical care setting to improve therapeutic efficacy and to reduce adverse consequences.

This study had a few limitations one of them being a retrospective study with limited time duration and small sample size without any intervention component and absence of clinical correlation.

\section{CONCLUSION}

There is an increased prevalence of pDDI in critical care setting with the majority of them being clinically significant. With polypharmacy be- ing a common problem due to the increased number of diagnosis and associated comorbid disorders in critically ill patients there is a need for increased special safety measures to monitor and prevent potential drug-drug interaction. Using suitable software or with the help of clinical pharmacist who will be responsible for monitoring of drug interaction and their notification to a physician about potential problems can reduce the prevalence. There is also a need for specialized studies with clinical correlation and continued education program for health care providers in optimizing therapeutic regimens to provide better health care quality.

\section{ACKNOWLEDGEMENT}

We acknowledge the support of medical superintendent and Medical record section staff for their support for the collection of data.

\section{CONFLICT OF INTEREST}

The authors declare no conlfict of interest.

\section{ABBREVIATIONS}

pDDI: Potential Drug Drug Interaction; DDI: Drug Drug Interaction; ICU: Intensive Care Unit; Qtc: QT Interval in ECG; NA: Not available.

\section{REFERENCES}

1. Hartshorn EA. Evolution of drug-drug interactions: a personal viewpoint. Ann Pharmacother. 2006;40(1):112-3

2. Zhou SF, Xue CC, Yu XQ, Li C, Wang G. Clinically important drug interactions potentially involving mechanism-based inhibition of cytochrome P450 3A4 and the role of therapeutic drug monitoring. Ther Drug Monit. 2008;29(6):687-710.

3. Caterina P, Antonello DP, Chiara G, Chiara C, Giacomo L, Antonio S, et al. Pharmacokinetic drug-drug interaction and their implication in clinical management. J Res Med Sci. 2013;18(7):600-9.

4. Lima RE, DeBortoli CSH. Potential drug interactions in intensive care patients at a teaching hospital. Rev Lat Am Enfermagem. 2009;17(2):222-7.

5. Plaza J, Alamo M, Torres P, Fuentes A, Lopez F. Drug interactions and adverse events induced by drugs used in intensive care unit. Revista Med De Chile. 2010;138(4):452-60

6. Classen DC, Pestotnik SL, Evans RS, Lloyd JF, Burke JP. Adverse drug events in hospitalized patients. Excess length of stay, extra costs and attributable mortality. JAMA. 1997;277(4):301-6.

7. Grizzle AJ, Mahmood MH, Ko Y, Murphy JE, Armstrong EP, Skrepnek GH, et al. Reasons provided by prescribers when overriding drug-drug interaction alerts. Am J Manag Care. 2007;13(10):573-8

8. Zwart-van RJEF, Uijtendaal EV, Ten BMJ, Solinge WWV, Egberts ACG. Frequency and nature of drug-drug interactions in a Dutch university hospital. Br J Clin Pharmacol. 2009;8(2):187-93.

9. Smithburger PL, Kane-Gill SL, Seybert AL. Drug-drug interactions in the medical intensive care unit: an assessment of frequency, severity and the medications involved. Int J Pharm Pract. 2012;20(6):402-8.

10. Hammes JA, Pfuetzenreiter F, Silveira FD, Koenig A, Westphal GA. Potential drug interactions prevalence in intensive care units. Rev Bras Ter Intensiva. 2008;20(4):349-54.

11. Abideen S, Vivekanandan K, Mishra P. Assessment of prevalence of potential drug-drug interactions in medical intensive care unit of a tertiary care hospital in India. Asian J Pharm Clin Res. 2015;8(1):125-30

12. Kumar MA, Nizar A, Shailaja K, Jayasutha J, Ramasamy C. A study on prescribing pattern and potential drug-drug interactions in type 2 diabetes mellitus (inpatients) in a tertiary care teaching hospital. Der Pharmacia Lettre. 2011;3(4):13-9.

13. Paterno MD, Maviglia, SM, Gorman PN, Seger DL, Yoshida E, Seger AC, et al Tiering Drug interaction alerts by severity increases compliance rates. J Am Med Inform Assoc. 2009;16(1):40-6.

14. Hamidy YM, Fauzia D. Significant drug interactions among intensive care unit patients. Asian Journal of Pharmaceuticals and Clinical Research. 2017;10(14):35-

15. Gupta M, Chincholkar AS, Wagh RJ, Maheshwari N, Siddiqui W. A study of potential drug-drug interactions among critically ill patients at a tertiary care hospital. Int J Basic Clin Pharmacol. 2016;5:1281-5.

16. Valizade $H$, Mohammad A, Sharifi $H$, Hasanzadeh A. Drug-Drug Interactions Prevalence in Intensive Care Unit patients of university hospital in Iran. Bull Env Pharmacol Life Sci. 2014;3(7):87-91.

17. Bleich GW, Bleich A, Chiamulera P, Sanches AC, Schneider DS, Teixeira JV, et al. Frequency of potential interactions between drugs in medical prescriptions in a city in southern Brazil. Sao Paulo Med J. 2009;127(4):206-10. 
18. Hasan SS, Lim KN, Anwar M, Sathvik BS, Ahmadi K, Yuan AW, et al. Impact of pharmacists' intervention on identification and management of drug-drug interactions in an intensive care setting. Singap Med J. 2012;53(8):526-31.

19. Ray S, Pramanik J, Bhattacharyya M, Todi S. Prospective observational evaluation of incidences and implications of drug-drug interactions induced adverse drug reactions in critically ill patients. Indian J Pharm Sci. 2010;72(6):787-92.

20. Haji AM, Sistanizad M, Abbasinazari M, Abiar GM, Ayazkhoo L, Safi O, et al. Potential drug-drug interactions in post-CCU of a teaching hospital. Iran J Pharm Res. 2013;12(1):243-8.

21. Alvim MM, Silva LA, Leite IC, Silvério MS. Adverse events caused by potential drug-drug interactions in an intensive care unit of a teaching hospital. Rev Bras Ter Intensiva. 2015;27(4):353-9.

22. Bista D, Saha A, Mishra P, Palaian S, Shankar PR. Impact of educational intervention on the pattern and incidence of potential drug-drug interactions in Nepal. Pharm Pract. 2009;7(4):242-7.

23. Kothari N, Ganguly B. Potential drug-drug interactions among medications prescribed to hypertensive patients. J Clin Diagn Res. 2014;8(11):1-4.

24. Baniasadi S, Farzanegan B, Alehashem M. Important drug classes associated with potential drug-drug interactions in critically ill patients: highlights for cardiothoracic intensivists. Ann Intensive Care. 2015;5(1):44.

Article History: Submission Date : 20-11-2018; Revised Date : 03-02-2019; Acceptance Date : 21-02-2019.

Cite this article: Acharya S, Ragam AS, Holla R, Bhat ARAY. Prevalence of Potential Drug-Drug Interactions in the Intensive Care Unit of a Tertiary Care Hospital: A Cross-Sectional Study. J Young Pharm. 2019;11(2):197-201. 